\title{
Regulation of Cortical and Subcortical Glutamate Receptor Subunit Expression by Antipsychotic Drugs
}

\author{
Lawrence W. Fitzgerald, ${ }^{1}$ Ariel Y. Deutch, ${ }^{1}$ Gregory Gasic, ${ }^{2}$ Stephen F. Heinemann,, ${ }^{2}$ and Eric J. Nestler ${ }^{1}$ \\ 'Laboratory of Molecular Psychiatry, Departments of Psychiatry and Pharmacology, Yale University School of \\ Medicine, New Haven, Connecticut 06508, and '2Molecular Neurobiology Laboratory, The Salk Institute, San Diego, \\ California 92186
}

Because glutamate is an important modulator of subcortical dopamine (DA) function, and abnormal glutamate/DA interactions may be involved in the pathophysiology of schizophrenia, we examined the effect of chronically administered antipsychotic drugs (APDs) on the levels of specific glutamate receptor subunits in the terminal fields of nigrostriatal and mesocorticolimbic DA systems. By immunoblotting procedures using antibodies specific for the NMDAR1, GluR1, and GluR2 subunits, we found that haloperidol (predominantly a $D_{2}$-like antagonist) increased NMDAR1 subunit immunoreactivity (and mRNA levels) in the striatum, while the $D_{1}$-like antagonist SCH 23390 had the opposite effect. No effect was seen on GluR1 or GluR2 levels. The result that $D_{1}$-like and $D_{2}$-like receptor antagonism can reciprocally regulate NMDAR1 expression is consistent with our observation that complete unilateral destruction of the nigrostriatal DA pathway with 6-hydroxydopamine had no effect on striatal NMDAR1 subunit levels. Further examination of these striatal effects revealed that chronic treatment with the $D_{2}$-like receptor antagonist raclopride significantly increased NMDAR1 levels in the striatum, while the 5-HT2a/2c antagonist mianserin tended to produce an increase that did not achieve statistical significance. These findings indicate that the dopaminergic antagonist properties of haloperidol are likely most responsible for its regulation of this subunit. In contrast, the atypical APD clozapine had no effect on striatal NMDAR1 levels, consistent with the relatively weaker influence of this drug on nigrostriatal DA function. The second major finding of the present study was the ability of haloperidol and clozapine to increase GluR1 levels in the medial prefrontal cortex (PFC), whereas chronic SCH 23390 treatment decreased GluR1 levels. The failure of mianserin to influ-

\footnotetext{
Received July 18, 1994; revised Sept. 30, 1994; accepted Oct. 10, 1994.

We thank Drs. Nils Brose (University of Texas), Robert Wenthold (National Institutes of Health), and John Morrison (Mount Sinai School of Medicine) for kindly providing anti-NMDAR1, GluR1, and GluR2 antibodies, respectively We also thank Dr. Peter Jatlow (Yale University) for determining plasma haloperidol levels. This work was supported by USPHS Grants DA08227, DA00203 (E.J.N.), MH45124 (A.Y.D.), P01-MH25642 (A.Y.D., E.J.N.), NS28709 (S.F.H.), and P32-NS07136 (L.W.F.), and by the National Parkinson's Foundation Center at Yale University (A.Y.D.), VA Schizophrenia National Research Center (A.Y.D., E.J.N.), The McKnight Foundation (S.F.H.), and the Abraham Ribicoff Research Facilities, Connecticut Mental Health Center, State of Connecticut Department of Mental Health.

Correspondence should be addressed to Eric J. Nestler, M.D., Ph.D., Department of Psychiatry, Connecticut Mental Health Center, Yale University School of Medicine, 34 Park Street, New Haven, CT 06508.

Copyright (C) 1995 Society for Neuroscience $0270-6474 / 95 / 152453-09 \$ 05.00 / 0$
}

ence GluR1 levels in the PFC is consistent with the notion that $D_{1}-$ and $D_{2}$-like receptor antagonists can reciprocally regulate this subunit in this brain region. Finally, we observed that clozapine, but none of the other treatments examined, increased GluR2 levels in the frontal/parietal cortex, nucleus accumbens, and hippocampus. The regionally distinct effects of various APDs on levels of particular glutamate receptor subunits may be related to cell-specific expression patterns of these subunits in different forebrain sites. Regulation of glutamate receptor subunits may be an important and novel mechanism through which APDs exert some of their long-term effects on brain function.

[Key words: prefrontal cortex, schizophrenia, clozapine, striatum, dopamine, NMDA]

Studies directed at understanding the mechanism of action of antipsychotic drugs (APDs) are rooted in the prospect that they may contribute to the development of improved pharmacotherapeutic agents and to the identification of biological processes underlying schizophrenia. APDs are most known for their ability to acutely block dopamine (DA) receptors, a characteristic that supports an important role of DA in this illness (Peroutka and Snyder, 1980). It is generally recognized, however, that the maximal antipsychotic actions of these drugs require chronic administration and probably involve direct or indirect interactions with numerous other neurochemical systems and, perhaps, alterations in gene expression (e.g., Meltzer, 1991; Hyman and Nestler, 1993; Lieberman, 1993).

APDs appear to affect, at least indirectly, forebrain systems that utilize glutamate (e.g., Daly and Moghaddam, 1993), the principle excitatory neurotransmitter in the brain. There is growing evidence that glutamate, by means of functional and anatomical interactions with nigrostriatal and mesocorticolimbic DA systems, plays a critical role in regulating conditional, emotional, and motivational aspects of motor function in the mammalian CNS (Carlsson and Carlsson, 1990). Predictably, dysfunction in DA/glutamate interactions may contribute to a number of neuropsychiatric abnormalities including hyper- and hypokinetic movement disorders and schizophrenia (Weinberger, 1987; Albin et al., 1989; Deutch, 1993; Grace, 1993; Krystal et al., 1994).

Glutamate interacts with central DA systems via several types of receptors, which include the ionotropic $N$-methyl-D-aspartate (NMDA), $\alpha$-amino-3-hydroxy-5-methyl-4-isoxazoleproprionic

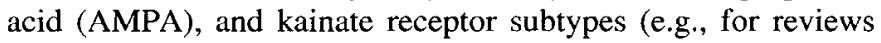
see Monaghan et al., 1989; Hollmann and Heinemann, 1994). All of these receptors are oligomers of individually encoded subunits, a feature which likely contributes to their physiological 
diversity. NMDA receptor subunits (NMDAR1, NMDAR2A-D) (Moriyoshi et al., 1991; Monyer et al., 1992; Ishii et al., 1993) combine to form a cationic ionophore with distinct, pharmacologically defined binding sites for glutamate, glycine, polyamines, and the dissociative anesthetics (ketamine, MK-801, and phencyclidine), as well as voltage-sensitive regulatory sites for $\mathrm{Mg}^{2+}$ (for reviews see Monaghan et al., 1989; Hollmann and Heinemann, 1994). The NMDAR1 subunit is expressed ubiquitously in brain and is required for the normal function of the NMDA ionophore (Moriyoshi et al., 1991; Petralia et al., 1994). NMDAR2 subunits are more discretcly localized and appear to serve a modulatory role in NMDA channel function (Ishii et al., 1993). AMPA and kainate receptors, respectively, are composed of GluR1-GluR4 (Hollmann et al., 1989; Boulter et al., 1990) and GluR5-7 and KA1-2 subunits (Bettler et al., 1990; Werner et al., 1991; Hollmann and Heinemann, 1994); unlike the NMDA receptor complex, these receptors evoke fast voltageindependent synaptic responses (e.g., for review see Nakinishi, 1992; Hollmann and Heinemann, 1994). In addition to mediating fast neurotransmission in the brain, glutamate receptors play key roles in many forms of neural plasticity, such as learning and memory, neural ontogeny, and functional compensations to tissue injury (e.g., for review see Collingridge and Singer, 1990; Anwyl, 1991). Whether glutamate receptors contribute to the neural plasticity implicated in the therapeutic actions of chronically administered APDs is unknown.

Because of glutamate's interactions with central DA systems under normal and, presumably, pathophysiological conditions, we sought to examine the regulation of glutamate receptors in DA terminal regions after chronic APD treatment. In so doing, we have taken advantage of recently characterized antibodies that are highly sensitive and specitic for the NMDARl, GluR1, and GluR2 subunits (Wenthold et al., 1992; Puchalski et al., 1994; Seigel et al., 1994). This approach permits a specific analysis of the regulatory characteristics of individual subunit proteins within anatomically discrete brain regions, and circumvents some difficulties associated with the use of classical radioligand binding techniques to assess glutamate receptor function (for discussion, see Trevisan et al., 1994). We show here that regionspecific regulation of glutamate receptor subunits may be a novel mechanism by which chronically administered APDs exert some of their long-term effects on brain function.

\section{Materials and Methods}

Chronic drug treatments and 6-OHDA lesions of the nigrostriatal DA pathway. Male Sprague-Dawley rats (initial weight 200-280 gm, CAMM, PA) were group housed 3-4/cage under a $12 \mathrm{hr}$ light-dark cycle (lights on at 7 A.M.) and permitted food and water ad libitum. Different groups of rats received chronic treatments with haloperidol (Sigma), clozapine (Sandoz), raclopride (Astra), SCH 23390 (Research Biochemicals, Inc.), or mianserin (Research Biochemicals, Inc.). Each drug treatment group was matched to its own group of control animals. Oral treatment regimens were selected over parenteral approaches whenever possible in order to provide more stable and continuous levels of the APD to mimic the clinical situation. These doses were generally set higher than parenteral dosages typically reported in the literature in order to account for first-pass metabolic effects on bioavailability (See and Ellison, 1990). Control rats for the oral haloperidol and clozapine regimens received unrestricted tap water that had been $\mathrm{pH}$ adjusted with dilute acetic acid in order to match the $\mathrm{pH}$ levels of the drug solutions; control rats for raclopride received normal tap water; and those in injection regimens received vehicle injections $(0.9 \%$ saline, i.p.).

The selection of equivalent doses for various APDs is essential in order to definitively attribute the differential actions of the compounds to their distinct pharmacodynamic properties. Unfortunately, while several approaches can be employed to set comparable dose of APDs, none are completely satisfactory. For example, selecting a dose of haloperidol on the basis of its F. $D_{50}$ for competition against a $D_{2}$ antagonist (e.g., spiperone) results in a dose that is quite low relative to those used in most chronic studies $\left(\mathrm{ED}_{50}=0.18 \mathrm{mg} / \mathrm{kg}\right.$; Csernansky et al., 1993). Moreover, matching this against an $\mathrm{ED}_{50}$ for clozapine of $19.4 \mathrm{mg} / \mathrm{kg}$ using the same paradigm results in a ratio of clozapine:haloperidol (100: 1) which far exceeds the 20-30:1 ratio typically observed in clinical practice.

Therefore, in the present study we chose to select a dose of haloperidol which, in preliminary studies, produced plasma haloperidol concentrations that were clinically relevant. Using this dose as a reference point, we then selected doses of clozapine and raclopride on the basis of clinical equivalency. Haloperidol was prepared in a minimal volume of acetic acid as described previously (See and Ellison, 1990), and delivered in the drinking water $(0.025 \mathrm{mg} / \mathrm{ml}, \mathrm{pH} 6.5)$ for 7 or $30 \mathrm{~d}$. The target dose for haloperidol $(1.8 \mathrm{mg} / \mathrm{kg} / \mathrm{d})$, chosen based on previous dosing in rats that had been extrapolated from human clinical dosages (Titeler and Seeman, 1980; Rupniak et al., 1984; See and Ellison, 1990), resulted in plasma haloperidol concentrations after $30 \mathrm{~d}$ (mean $=13$ $\mathrm{ng} / \mathrm{ml}, n=3$, as determined by HPLC) in the midtherapeutic range (Volavka et al., 1992). This regimen has been shown previously to produce DA $D_{2}$-like receptor supersensitivity (Rupniak et al., 1984) in rodents. Clozapine was prepared in a minimal volume of acetic acid and delivered in the drinking water $(0.5 \mathrm{mg} / \mathrm{ml}, \mathrm{pH} 6.0)$ as described previously (See and Ellison, 1990) for 7 or $25 \mathrm{~d}$, with an average daily intake of 40 and $35 \mathrm{mg} / \mathrm{kg}$, respectively. A sustained delivery of drug via the drinking water seemed particularly important for clozapine, given its reported rapid elimination from brain (e.g., after $10 \mathrm{mg} / \mathrm{kg}$ i.p., $\left.t_{1 / 2}=1.5-1.6 \mathrm{hr}\right)$ and its inability to accumulate in brain over chronic intermittent dosing (Wilk and Stanley, 1978; Baldessarini et al., 1993). This dose of clozapine was chosen based on the 20-30-fold difference in the doses of clozapine and haloperidol used clinically. Raclopride was delivered in the drinking water $(0.02 \mathrm{Img} / \mathrm{mml} ; 2.2 \mathrm{mg} / \mathrm{kg} / \mathrm{d}$ ) for 34 $\mathrm{d}$ as described previously (See and Ellison, 1990). This dose of raclopride, equivalent to that used for haloperidol, was chosen based on similar therapeutic ranges of the two drugs (Tamminga and Gerlach, 1987; Farde et al., 1988).

Doses for the other drugs were selected on the basis of their demonstrated ability to produce long-term adaptive changes in signal transduction pathways in preclinical studies. SCH 23390 was administered twice daily $(0.5 \mathrm{mg} / \mathrm{kg}$, i.p.) for 3 weeks, a dosing regimen sufficient to produce $D_{1}$ receptor supersensitivity (e.g., Lappalainen et al., 1992). Mianserin was administered daily for $30 \mathrm{~d}(15 \mathrm{mg} / \mathrm{kg}$, i.p.). This regimen has been shown previously to elicit a downregulation of $5-\mathrm{HT}_{2}$ receptors (Roth and Ciaranello, 1991), a feature common to $5-\mathrm{HT}_{2 \mathrm{a} / \mathrm{zc}}$ receptor antagonists including clozapine (Reynolds et al., 1983; Leysen et al., 1986). Rats receiving oral treatments were killed without withdrawal, whereas rats receiving injection regimens were used $16-18 \mathrm{hr}$ after their last treatment.

One group of rats received unilateral 6-hydroxydopamine (6-OHDA) lesions of the nigrostriatal DA pathway. Rats were anesthetized with chloral hydrate/pentobarbital, and $1.5 \mu \mathrm{l}$ of $6-\mathrm{OHDA}-\mathrm{HBr}(4 \mu \mathrm{m}$ free base/ $\mu$; Sigma) was injected stereotaxically into the substantia nigra (AP -5.3, L 1.7, DV -8.2) and ventral tegmental area (AP -5.3, L 0.8 , DV -8.4). The extent of striatal denervation was assessed by measuring tyrosine hydroxylase immunoreactivity in the striata as described previously (Beitner-Johnson and Nestler, 1991). All rats used in the present study were killed 30 d postlesioning and exhibited a >95\% loss in striatal tyrosine hydroxylase.

Western blot analyses. Brains were removed rapidly from decapitated rats and chilled in ice-cold buffer ( $\mathrm{pH} 7.4$ ) containing $126 \mathrm{~mm} \mathrm{NaCl}, 5$ $\mathrm{mM} \mathrm{KCl}, 1.25 \mathrm{mM} \mathrm{NaH} \mathrm{PO}_{4}, 25 \mathrm{~mm} \mathrm{NaHCO}_{3}, 2 \mathrm{~mm} \mathrm{CaCl}, 2 \mathrm{~mm}$ $\mathrm{MgCl}_{2}$, and $10 \mathrm{~mm} \mathrm{D}$-glucose. Brain regions were isolated by gross dissection or from two $1 \mathrm{~mm}$ coronal sections (approximately $+3.7-$ 2.7 , and $+2.2-1.2$ relative to bregma) using the rat atlas of Paxinos and Watson (1986). Bilateral tissue samples were homogenized in $2 \%$ sodium dodecyl sulfate (SDS) and protein levels were determined by the method of Lowry. Samples were adjusted to contain (final concentration) $50 \mathrm{~mm}$ Tris-IICl, pII 6.7, 4\% glycerol, $4 \%$ SDS, $2 \%$ 2-mcrcaptoethanol, and bromophenol blue as a marker, and then boiled for 3 min. Samples (10-20 $\mu \mathrm{g}$ protein) were subjected to SDS-polyacrylamide gel electrophoresis with $7.5 \%$ acrylamide $/ 0.3 \%$ bis-acrylamide in the resolving gels. Proteins were transferred electrophoretically to nitrocellulose papers. The NMDAR1 subunit $\left(\mathrm{M}_{r} 116 \mathrm{kDa}\right)$ was immunolabeled using a mouse monoclonal antibody (MAb 54.1; diluted 
Table 1. Glutamate receptor subunit immunoreactivity after chronic haloperidol

\begin{tabular}{lccc} 
Region & NMDAR1 & GluR1 & GluR2 \\
\hline $\begin{array}{l}\text { Frontal-parietal } \\
\quad \text { cortex }\end{array}$ & $112 \pm 11$ & $100 \pm 9$ & $109 \pm 10$ \\
$\begin{array}{l}\text { Medial prefrontal } \\
\quad \text { cortex }\end{array}$ & $110 \pm 16$ & $\mathbf{1 4 0} \pm \mathbf{1 4} *$ & $100 \pm 13$ \\
Posterior cingulate cortex & $\mathbf{1 7 0} \pm \mathbf{2 8}^{*}$ & $94 \pm 7$ & $116 \pm 12$ \\
Striatum & $\mathbf{1 4 0} \pm \mathbf{1 0}^{*}$ & $113 \pm 9$ & $100 \pm 9$ \\
Nucleus accumbens & $91 \pm 17$ & $96 \pm 5$ & $99 \pm 23$ \\
Hippocampus & $94 \pm 7$ & $90 \pm 11$ & $87 \pm 10$
\end{tabular}

Data are expressed as percentage of control \pm SEM.

* Significantly different from controls, $p<0.05\left(\chi^{2}\right.$ tests $)$. These data were derived from two independent experiments (combined $n=12 /$ treatment group). See Materials and Methods for details.

1:5000) which was raised against a bacterial trpE fusion protein corresponding to NMDAR1 residues $660-811$, a region which represents a putative intracellular loop between transmembrane regions III and IV (Siegel et al., 1994). The GluR2 subunit (M, $108 \mathrm{kDa}$ ) was immunolabeled using a mouse monoclonal antibody (MAb 3A11; diluted 1:2000) which was generated against a fusion protein from the N-terminal, putative extracellular domain of GluR2 (Puchalski et al., 1994). This is the only known MAb that differentiates GluR2 from the GluR3 subunit. The GluR1 subunit $\left(\mathrm{M}_{r} 108 \mathrm{kDa}\right)$ was immunolabeled using a rabbit polyclonal antiserum (Ab9; diluted 1:2000) which was generated against the C-terminal sequence SHSSGMPLGATGL (residues 877889) (Wenthold et al., 1992). We also used a specific antiserum directed against GluR4 in preliminary experiments (Wenthold et al., 1992). All immunoblotting buffers contained $20 \mathrm{~mm}$ sodium phosphate $(\mathrm{pH} 7.4)$, $150 \mathrm{~mm} \mathrm{NaCl}, 0.05 \%$ Tween (Sigma), and $0.5 \%$ nonfat dry milk as the blocking agent. Proteins were detected using horseradish peroxidaseconjugated IgG (diluted 1:2000; Vector Laboratories) followed by chemiluminescence (New England Nuclear, Dupont). Levels of immunoreactivity were quantitated using computer-assisted densitometry and were linear over at least a 3-fold range of tissue concentration.

Northern blot analyses. Rats were treated with haloperidol for $30 \mathrm{~d}$ and total RNA was isolated from pooled tissue by centrifugation over a $\mathrm{CsCl}$ gradient according to established procedures. The resulting RNA pellets were suspended in $0.3 \mathrm{M}$ sodium acetate, $\mathrm{pH} 6.0$, and precipitated with $2.5 \mathrm{vol}$ of ethanol on dry ice. Total RNA $(15 \mu \mathrm{g})$ was fractionated on a $1 \%$ agarose gel containing $66 \mathrm{~mm}$ formaldehyde and then transferred to supported nitrocellulose membranes. Vector containing the entire coding region of the NMDAR1 gene was linearized by BamH1 digestion and transcribed with T7 RNA polymerase using $\left[\alpha-{ }^{32} \mathrm{P}\right] \mathrm{rCTP}$. Membranes were prehybridized for $3 \mathrm{hr}$ at $65^{\circ} \mathrm{C}$ in buffer containing $50 \mathrm{~mm}$ Tris- $\mathrm{HCl}, \mathrm{pH} 7.5,0.1 \%$ sodium pyrophosphate, $1 \%$ SDS, $0.2 \%$ polyvinylpyrrolidone (MW 40,000), $0.2 \%$ ficoll, $0.2 \%$ bovine serum albumin (fraction V), $5 \mathrm{~mm}$ EDTA, 50\% deionized formamide, $5 \times \mathrm{SSC}$, and $150 \mu \mathrm{g} / \mathrm{ml}$ denatured salmon sperm DNA.

Hybridizations were carried out for $18 \mathrm{hr}$ at $65^{\circ} \mathrm{C}$ in the same buffer containing $1 \times 10^{6} \mathrm{cpm}$ of the labeled riboprobe. The membranes were washed twice for $15 \mathrm{~min}$ in $2 \times \mathrm{SSC}, 0.1 \%$ SDS at $65^{\circ} \mathrm{C}$, and twice for $15 \mathrm{~min}$ in $0.1 \times \mathrm{SSC}, 0.1 \% \mathrm{SDS}$ at $65^{\circ} \mathrm{C}$. Comparable levels of loaded total RNA were confirmed by rehybridizing blots with an $\left[\alpha-{ }^{32} \mathrm{P}\right] \mathrm{dCTP}-$ random prime-labeled cDNA fragment for cyclophilin. The membranes were air dried and the labeled bands were detected by autoradiography.

Statistical analyses. Optical densities from the chronic haloperidol experiments were first converted to percent of control values and then analyzed by $\chi^{2}$ tests. This enabled the analysis of replicates (from two independent experiments of six rats per treatment group, see Table 1 for more details) of data obtained on different days in which there was variation in the intensity of the immunolabeling. For the other experiments which did not involve replicate experiments, optical density values were analyzed by nonparametric Mann-Whitney $U$ tests and then expressed and presented as mean percent of control values for graphic clarity.

\section{Results}

Regional distribution of the NMDARI, GluR1, and GluR2 subunits as determined by Western blotting

Immunoblot analysis of crude SDS extracts of brain shows labeling of NMDAR1 by MAb 54.1 as a single immunoreactive band with an estimated mass of $116 \mathrm{kDa}$ (Fig. 1A). Immunoblot analysis using antibodies against GluR1 (Ab9) or GluR2 (MAb 3A11) produced immunoreactive bands of approximately 108 $\mathrm{kDa}$ (see Fig. $1 B, C$ ). The specificity of these antibodies for use in Western blotting has been established elsewhere (Wenthold et al., 1992; Puchalski et al., 1994; Siegel et al., 1994). Whereas the anti-GluR1 antibody recognized a single band, the antiGluR2 antibody recognized a tightly spaced doublet in some experiments as shown in Figure $1 C$. This may reflect pre- or
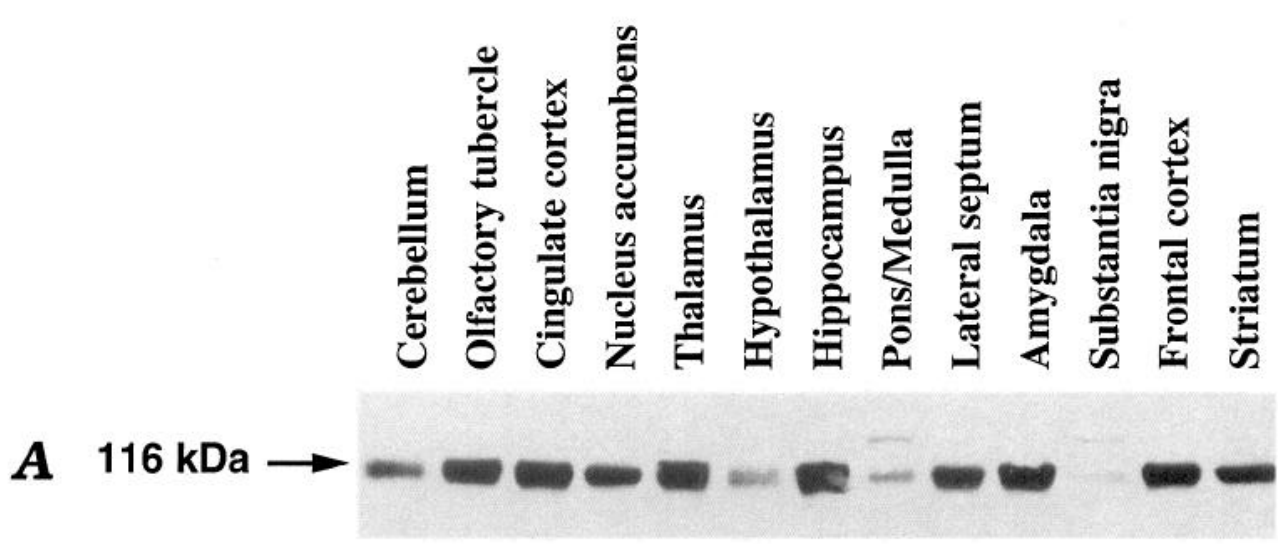

B $108 \mathrm{kDa}$
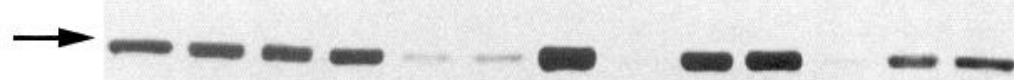

C $\quad 108 \mathrm{kDa}$
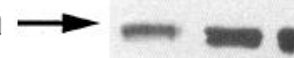

Figure 1. Regional distribution of NMDAR1, GluR1, and GluR2 subunits in rat brain. Aliquots (containing $20 \mu \mathrm{g}$ protein) of crude homogenates were subjected to SDS-polyacrylamide gel electrophoresis and to immunoblotting for NMDAR1 $(A)$, GluR1 $(B)$, or GluR2 $(C)$ as described in Materials and Methods. Similar distribution patterns were observed in the two naive rats analyzed. 
Figure 2. Region- and subunit-specific regulation of glutamate receptor immunoreactivity by chronic haloperidol and SCH 23390 treatments. Rats were treated chronically with haloperidol $(A)$ or SCH $23390(B)$, after which time crude homogenates were subjected to SDS-polyacrylamide gel electrophoresis and immunoblotting as described in Materials and Methods. Refer to Tables 1 and 2 for a quantitative presentation of the data. $H$, haloperidol; $S, \mathrm{SCH}$ 23390; C, control; CING CTX, cingulate cortex; $N A C$, nucleus accumbens; PFC, medial prefrontal cortex. Arrows point to representative autoradiograms depicting significant group differences.
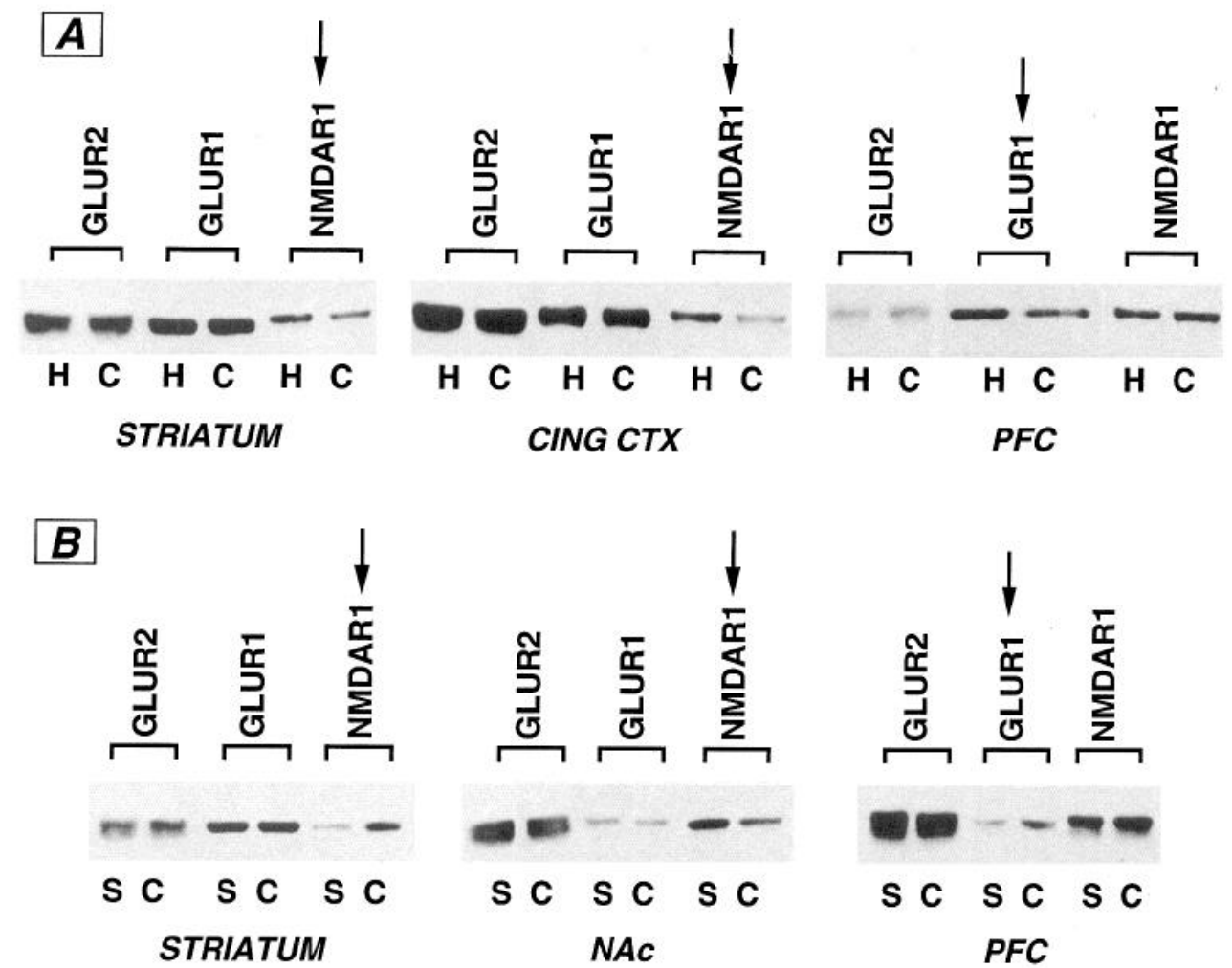

post-translational heterogeneity in GluR2 or, alternatively, may represent degradation products from the major immunoreactive band.

NMDAR1, GluR1, and GluR2 showed very similar regional distributions in brain with high levels of the proteins seen in

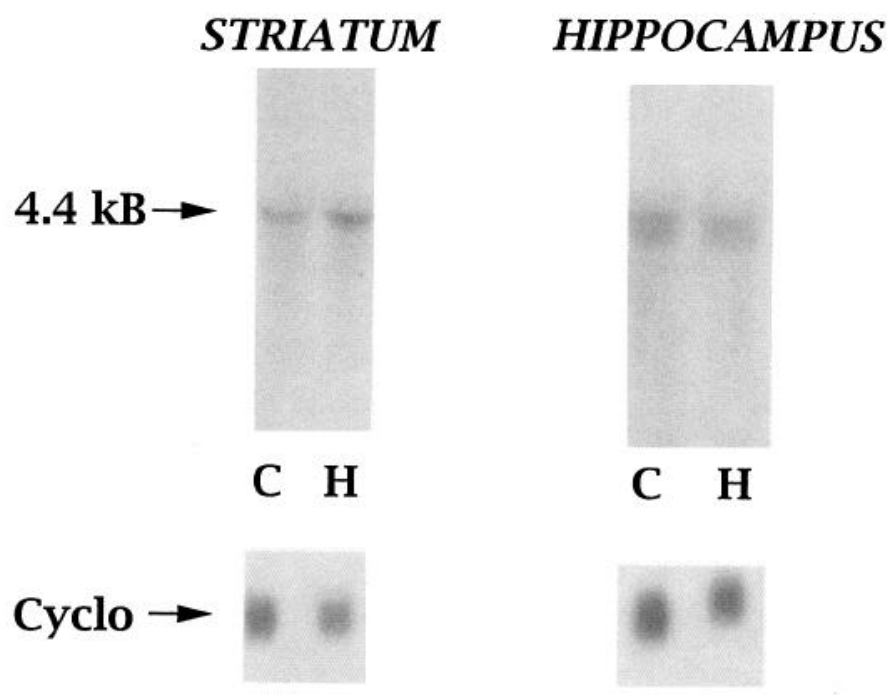

Figure 3. Regulation of NMDAR1 subunit mRNA in striatum, but not hippocampus, by chronic haloperidol treatment. Total RNA $(15 \mu \mathrm{g})$ was extracted from brain regions isolated from control and haloperidol-treated rats and subjected to electrophoresis in $1 \%$ agarose gels. RNA was transferred electrophoretically to supported nitrocellulose, which was then analyzed by Northern blotting using a ${ }^{32} \mathrm{P}$-labeled riboprobe for NMDAR1. The same blots were reprobed for cyclophilin to insure each lane had comparable levels of RNA. This figure is representative of results obtained from three separate determinations, with each determination made on RNA isolated from striatal and hippocampal samples pooled from two rats. cortical regions, striatum, nucleus accumbens, hippocampus, and pons/medulla, and hypothalamus. One notable difference, however, is that NMDAR 1 subunit protein is much more abundant in the thalamus (relative to other regions) than GluR1 and GluR2 (AMPA) subunit protein. In contrast, GluR4 immunoreactivity showed a much more restricted distribution in brain, with significant levels seen in the cerebellum only (data not shown). Since this brain region is generally not implicated in the therapeutic effects of APDs, we opted not to examine APD regulation of this subunit. We were unable to study the GluR3 subunit due to the unavailability of a specific antibody.

\section{Effects of chronic and subchronic treatment with haloperidol on glutamate receptor subunit immunoreactivity}

As an initial investigation of APD regulation of glutamate receptor subunits, we chose to study haloperidol, a standard typical APD that potently blocks $\mathrm{DA}_{2}$-like receptors as well as several others (e.g., $\alpha_{1}$-adrenergic, 5-HT $\mathrm{H}_{2 \mathrm{a} / \mathrm{c}}$ serotonergic, and $\mathrm{D}_{1}$-like dopaminergic receptors) with low-to-moderate affinity. Haloperidol was administered for 7 or $30 \mathrm{~d}$ and the levels of immunoreactivity of the NMDAR1, GluR1, and GluR2 subunits were examined in the striatum, medial prefrontal cortex (PFC), posterior cingulate cortex, frontal-parietal (sensorimotor) cortex, nucleus accumbens, and hippocampus. Haloperidol treatment for $30 \mathrm{~d}$ significantly increased NMDAR 1 subunit immunoreactivity in the striatum and posterior cingulate cortex and GluR1 immunoreactivity in the medial prefrontal cortex (Table 1, Fig. 2A). No changes in these subunits were observed in the other regions studied. As shown in Figure 3, increased levels of NMDAR1 protein in the striatum were accompanied by an increase in mRNA levels for this protein as indicated by Northern blot analysis. Levels of GluR2 subunit immunoreactivity did not differ between control and treated rats in any of the regions examined. amygdala, and considerably lower levels in the substantia nigra, 


\begin{tabular}{|c|c|c|c|}
\hline Region & NMDAR1 & GluR1 & GluR2 \\
\hline $\begin{array}{l}\text { Frontal-parietal } \\
\text { cortex }\end{array}$ & $63 \pm 4^{*}$ & $63 \pm 9^{*}$ & $107 \pm 9$ \\
\hline $\begin{array}{l}\text { Medial prefrontal } \\
\text { cortex }\end{array}$ & $109 \pm 5$ & $66 \pm 12 *$ & $109 \pm 12$ \\
\hline Posterior cingulate cortex & $110 \pm 9$ & $99 \pm 15$ & $90 \pm 7$ \\
\hline Striatum & $67 \pm 10^{*}$ & $97 \pm 10$ & $103 \pm 11$ \\
\hline Nucleus accumbens & $153 \pm 16^{*}$ & $130 \pm 21$ & $119 \pm 12$ \\
\hline Hippocampus & $104 \pm 8$ & $116 \pm 10$ & $107 \pm 6$ \\
\hline
\end{tabular}

Data are expressed as percentage of control \pm SEM.

* Significantly different from controls, $p<0.05$ (Mann-Whitney $U$ tests), $N$ $=8-9$.

None of the changes in glutamate receptor subunit protein seen after $30 \mathrm{~d}$ of treatment with haloperidol were observed after shorter, subchronic (7 d) treatments (data not shown).

Pharmacological analysis of APD effects on glutamate receptor subunits: regulation by chronic $\mathrm{SCH} 23390$, clozapine, mianserin, raclopride, and nigrostriatal lesions

In order to further understand the mechanisms underlying haloperidol's effects on glutamate receptor subunits, we studied several other drugs with varied pharmacological profiles and antipsychotic efficacies. The first drug studied for comparison was SCH 23390 which, unlike haloperidol, is a potent $\mathrm{D}_{1}$-like antagonist with some $5-\mathrm{HT}_{2 \mathrm{a} / \mathrm{c}}$ antagonist properties. As shown in Table 2 and Figure $2 B$, rats treated chronically with SCH 23390 showed significant decreases in NMDAR1 immunoreactivity in the striatum and frontal/parietal cortex, but an increase in the nucleus accumbens. GluR1 immunoreactivity was significantly decreased in the PFC and frontal/parietal cortex. As with haloperidol, GluR2 subunit immunoreactivity was not altered by SCH 23390 treatment in any of the brain regions examined.

Since the potent $\mathrm{D}_{2}$-like antagonist haloperidol and the $\mathrm{D}_{1}$ like antagonist SCH 23390 had opposing actions on striatal NMDAR1 subunit levels in the striatum, we examined the effects of unilateral lesions of the nigrostriatal DA pathway (a treatment that removes $\mathrm{DA} \mathrm{D}_{1}$-like and $\mathrm{D}_{2}$-like receptor tone on striatal neurons) on NMDAR1 levels. As shown in Figure 4, complete lesions of the nigrostriatal pathway (as indicated by $>95 \%$ loss of striatal tyrosine hydroxylase immunoreactivity) had no influence on levels of NMDAR1. The lesions also had no effect on GluR1 or GluR2 immunoreactivities.

We next examined clozapine, an atypical APD that lacks extrapyramidal side effects (seen with all typical APDs) and exhibits unique efficacy in reducing the negative symptoms of schizophrenia (for reviews see Deutch et al., 1991; Meltzer, 1991). Like many APDs, clozapine has a broad pharmacological profile and antagonizes a number of receptors including DA $\mathrm{D}_{1}$-like and $\mathrm{D}_{2}$-like, muscarinic cholinergic, $\alpha$-adrenergic, and $5-\mathrm{HT}_{2 \mathrm{a} / 2 \mathrm{c}}$ receptors. As seen with haloperidol, chronic clozapine treatment significantly increased levels of GluR1 in the PFC (Table 3). Unlike any of the other drug treatments, however, clozapine increased GluR2 subunit levels in the frontal/parietal cortex, nucleus accumbens, and hippocampus. Also, unlike haloperidol and SCH 23390, clozapine did not alter NMDAR1 subunit protein in the striatum or any of the other brain regions examined. Furthermore, none of the changes in subunit levels

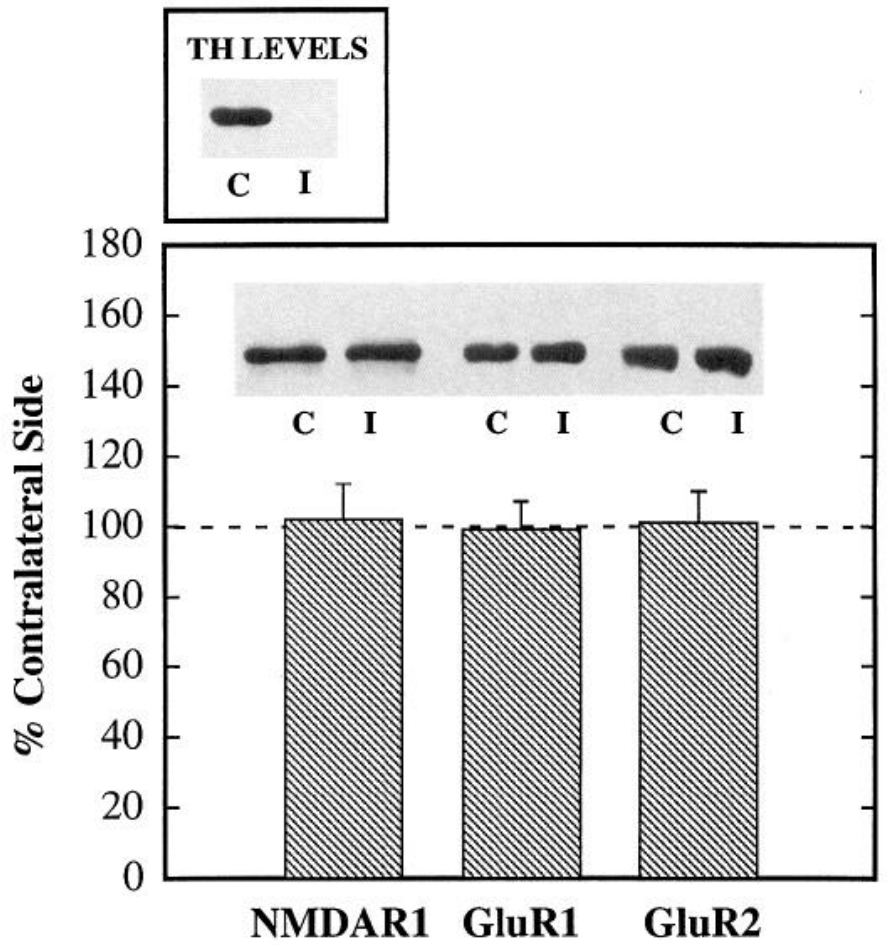

Figure 4. Levels of striatal glutamate receptor immunoreactivity after unilateral 6-OHDA lesioning of the nigrostriatal dopamine pathway. Rats received virtually complete $(>95 \%)$ unilateral 6-OHDA lesions to the substantia nigra as measured by tyrosine hydroxylase (TH) immunoreactivity. Data are derived from 6-7 rats, and expressed as percentage of the unlesioned side $( \pm$ SEM). Insets depict levels of glutamate receptor subunit and $\mathrm{TH}$ immunoreactivities in the striatum contralateral $(C)$ and ipsilateral $(I)$ to the side of the lesion.

observed in chronically treated rats were observed after the shorter, subchronic (7 d) regimen.

In order to clarify the extent to which serotonin and DA receptor antagonist properties alone may have contributed to the adaptations produced by haloperidol, SCH 23390, or clozapine in the striatum and PFC, we examined the effects of chronic mianserin (a 5- $\mathrm{HT}_{2 \mathrm{a} / \mathrm{c}}$ antagonist without $\mathrm{DA}$ receptor antagonist properties) and raclopride (a $\mathrm{D}_{2}$-like antagonist without serotonergic receptor antagonist properties) on glutamate receptor subunit levels in these brain regions. Raclopride significantly increased NMDAR1 levels in the striatum whereas mianserin tended to increase striatal NMDAR1 levels, although this effect

Table 3. Glutamate receptor subunit immunoreactivity after chronic clozapine*

\begin{tabular}{lrcc} 
Region & NMDAR1 & GluR1 & GluR2 \\
\hline $\begin{array}{l}\text { Frontal-parietal } \\
\quad \text { cortex }\end{array}$ & $93 \pm 3$ & $103 \pm 6$ & $\mathbf{1 2 9} \pm \mathbf{8}^{*}$ \\
$\begin{array}{l}\text { Medial prefrontal } \\
\quad \text { cortex }\end{array}$ & $95 \pm 5$ & $\mathbf{1 3 3} \pm \mathbf{1 1} *$ & $96 \pm 3$ \\
Posterior cingulate cortex & $94 \pm 5$ & $105 \pm 8$ & $97 \pm 3$ \\
Striatum & $115 \pm 8$ & $98 \pm 6$ & $101 \pm 4$ \\
$\quad$ Nucleus accumbens & $103 \pm 3$ & $104 \pm 6$ & $\mathbf{1 3 2} \pm \mathbf{5}^{* *}$ \\
Hippocampus & $102 \pm 5$ & $101 \pm 5$ & $\mathbf{1 2 1} \pm \mathbf{5}^{* *}$
\end{tabular}

Data are expressed as percentage of control \pm SEM.

* Significantly different from controls (Mann-Whitney $U$ tests, $p<0.05, N=$ $8-9)$. 


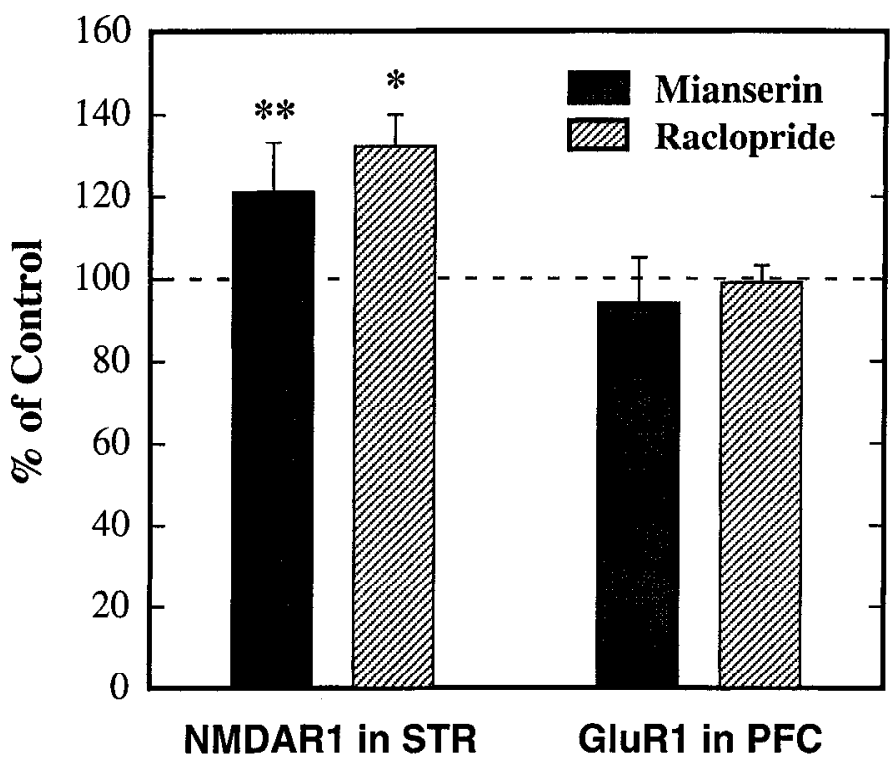

Figure 5. Pharmacological analysis of APD regulation of glutamate receptor subunit levels in the PFC and striatum: effects of chronic raclopride and mianserin treatments. Rats were treated chronically with raclopride (DA D -like antagonist; $n=8$ /group) or mianserin (5-HT antagonist; $n=8-9$ /group). Crude homogenates were subjected to SDSpolyacrylamide gel electrophoresis and immunoblotting as described in Materials and Methods. Raclopride significantly increased ${ }^{*} p=0.01$, Mann-Whitney $U$ test) NMDAR 1 levels in the striatum (STR), whereas mianserin produced a nonsignificant increase $(* * p=0.19$, Mann-Whitney $U$ test). Neither drug influenced GluR1 levels in the PFC.

did not achieve statistical significance. Neither raclopride nor mianserin affected GluR1 levels in the PFC (Fig. 5). Moreover, the ability of SCH 23390 to increase NMDAR1 levels in the nucleus accumbens, and the ability of clozapine to increase GluR2 levels in this brain region, were not mimicked by mianserin (data not shown).

\section{Discussion}

For the past 20 years, the antipsychotic and extrapyramidal potencies of typical APDs (e.g., haloperidol) have been widely attributed to the ability of these drugs to block $\mathrm{DA}_{2}$-like receptors (Creese et al., 1976). The more recent development of clinically cffectivc atypical drugs (e.g., clozapine), which are relatively less potent at DA $D_{2}$ receptors and demonstrate reduced extrapyramidal liability, has led to the examination of additional or alternative mechanisms of APD action (see introductory remarks).

The findings of the present study suggest that one such additional mechanism includes adaptations in central excitatory amino acid function, since we found region-specific regulation of glutamate receptor subunits by chronically administered typical and atypical APDs. In light of recent evidence that schizophrenia, as well as the extrapyramidal side effects of typical APDs (e.g., tardive dyskinesia), may involve abnormal DA-glutamate interactions, it is conceivable that adaptations in glutamate receptor function after chronic APD treatment may contribute to the clinical effects of these drugs. These findings also highlight an aspect of glutamate receptor regulation that has not been easily assessed by classical radioligand binding techniques: plasticity in glutamate receptor function may result directly from the differential regulation of individual subunits. This suggestion has important functional implications, considering that individ- ual receptor subunits are differentially distributed in the brain at the regional and cellular levels (Martin et al., 1993; Petralia et al., 1994), and combine to form oligomeric channels with sometimes diverse electrophysiological properties (for review see Hollmann and Heinemann, 1994)

One of the major findings of the present study is the plasticity of striatal NMDAR1 subunit in response to a variety of drugs. Haloperidol, predominantly a $D_{2}$-like receptor antagonist, increases NMDAR1 protein and mRNA levels in the striatum after chronic treatment, while SCH 23390 , predominantly a $\mathrm{D}_{1}$-like receptor antagonist, has the opposite effect. These findings suggest that $D_{1}$ - and $D_{2}$-like receptors exert an opposite influence on NMDAR1 subunit expression, an idea which is supported by our observation that lesions of the nigrostriatal pathway have no net effect on striatal NMDAR1 levels. Our finding is consistent with a recent report that these lesions do not affect NMDA receptor binding (Wüllner et al., 1993). However, since haloperidol and SCH 23390 also interact with other receptors (albeit with lower affinities) we examined the pharmacological specificity of these responses by using the $\mathrm{D}_{2}$-like antagonist raclopride (which lacks appreciable affinity for $\sigma$ sites and $5-\mathrm{HT}_{2 \mathrm{a} / 2 \mathrm{c}}$ receptors) and the 5- $\mathrm{HT}_{2 \mathrm{a} / 2 \mathrm{c}}$ antagonist mianserin (which lacks DA receptor antagonist properties). Since raclopride significantly increased NMDAR1 subunit levels in the striatum, while mianserin tended to produce an increase that was not statistically significant, haloperidol's effect is due largely to $\mathrm{D}_{2}$-like blockade whereas SCH 23390's effect is likely due to $\mathrm{D}_{1}$-like receptor blockade. Clozapine produced a small and nonsignificant increase $(+15 \%)$ in striatal NMDAR1 levels. The failure of clozapine to produce any significant striatal response may be due to the opposite actions of $\mathrm{D}_{1}$-like and $\mathrm{D}_{2}$-like receptor blockade (as seen with the 6-OHDA-treated rodent) on NMDAR1 levels since clozapine reportedly binds $\mathrm{D}_{1}$-like and $\mathrm{D}_{2}$-like receptors in vivo with nearly equal affinities (Andersen, 1988). It is also important to emphasize that interpretations of data based on comparisons of these various drugs must be viewed with caution given the difficulty in establishing clinically equivalent doses in the rat (see Materials and Methods).

Upregulation of NMDAR1 subunits by haloperidol and raclopride may occur as a compensatory response to the chronic suppression of the thalamocortical and corticostriatal glutamatergic drive that predictably results from high-affinity $\mathrm{DA}_{2}$ receptor blockade in the striatum (Albin et al., 1989; Gerfen, 1992). Indeed, a preliminary report by Penney et al. (1993) noted that striatal NMDA binding increased after cortical deafferentation. Haloperidol-induced increases in NMDAR 1 subunit levels in the posterior cingulate cortex may provide additional compensation in some corticofugal loops. Although the mechanism by which $\mathrm{D}_{1}$-like receptor blockade by $\mathrm{SCH} 23390$ downregulates striatal NMDAR1 subunits remains unknown, our data suggest that DA and cortical glutamate may differentially interact with functionally and anatomically segregated motor/limbic output pathways (e.g., $\mathrm{D}_{2}$-mediated striatopallidal and $\mathrm{D}_{1}$-mediated striatonigral pathways; Gerfen, 1992; Deutch, 1993; DiChiara et al., 1994). The opposite actions of haloperidol (or raclopride) and $\mathrm{SCH}$ 23390 on NMDAR1 levels may be a direct result of their varying influence on DA-mediated intracellular messengers [e.g., cAMP response element binding (CREB) protein, c-fos, and cAMP], since the promoter of the NMDAR1 gene has CRE, AP-1, and AP-2 regulatory elements (Bai and Kusiak, 1993).

Chronic haloperidol administration also has been shown to increase resting extracellular levels of glutamate in the striatum 
(Moghaddam, 1994). This finding, along with the observed increase in NMDAR1 subunit levels, would suggest that there may be a concerted upregulation in glutamate neurotransmission in the striatum in the haloperidol-treated state. It would be interesting to investigate this further as a mechanism for extrapyramidal side-effects, perhaps even excitotoxicity, associated with chronic haloperidol treatment.

A second major finding of the present study is the upregulation of GluRI subunit levels in the PFC by both haloperidol and clozapine treatments, and a significant decrease in subunit levels by SCH 23390 treatment. The inability of the $5-\mathrm{HT}_{2 a / 2 c}$ antagonist mianserin alone to mimic this effect suggests that, as seen with the NMDAR1 subunit in the striatum, $\mathrm{D}_{1}$ - and $\mathrm{D}_{2}$-like receptor blockade may have opposite effects on GluR1 subunit expression in the PFC. However, this interpretation is not as straightforward as for the striatum since raclopride conspicuously failed to regulate the GluR1 subunit in the PFC. There are at least two possibilities which could explain this result. Since mianserin alone had no effect, it is possible that GluR1 regulation requires concurrent $\mathrm{D}_{2}$-like/5- $\mathrm{HT}_{2 \mathrm{2} / \mathrm{c} \mathrm{c}}$ antagonism as provided by both haloperidol and clozapine. An alternative (and perhaps the more intriguing) possibility is that haloperidol and clozapine regulate GluR1 via blockade of cortical $\mathrm{D}_{4}$ receptors, while raclopride does not because it interacts with this receptor with relatively low affinity (Seeman et al., 1993). Direct investigation of this possibility requires the development of a specific $\mathrm{D}_{4}$ receptor antagonist, and a detailed map of DA $\mathrm{D}_{4}$ receptor protein and RNA expression in rodent brain.

The functional implications of APD regulation of GluR1 levels in the PFC are enhanced upon considering the cellular localization of this subunit in the PFC in relation to the current hypotheses regarding the pathophysiology of schizophrenia. Glutamatergic pyramidal neurons that project to subcortical targets are regulated by most major neurotransmitters including DA. As depicted in Figure 6, cortical DA inhibits these pyramidal neurons directly, or indirectly by increasing GABA release from interneurons (Retaux et al., 1991; Deutch, 1993; Gellman and Aghajanian, 1993; Grobin and Deutch, 1994). The removal of cortical DA, therefore, would be expected to increase DA release and metabolism in the nucleus accumbens and striatum by increasing the activity of glutamatergic pyramidal neurons which project to the vicinity of DA nerve terminals in these regions. Indeed, this has been observed in rodents, particularly those that are challenged with acute stress or haloperidol (Deutch, 1993). A possible role for dysfunctional corticostriatal/ accumbens circuits in schizophrenia gained support when Weinberger and colleagues, based on behavioral and imaging data, postulated that functional denervation of PFC DA may accompany enhanced subcortical DA function in schizophrenic patients (Weinberger, 1987; Berman and Weinberger, 1990). Evidence for reductions in the number of GABAergic interneurons (Benes et al., 1991; Akbarian et al., 1993) and compensatory increases in $\mathrm{GABA}_{\mathrm{A}}$ receptors (Benes et al., 1992) in the PFC of schizophrenic patients on autopsy further supports this notion of corticofugal disinhibition. Moreover, there is evidence in rodents that haloperidol increases GABA immunoreactivity in terminals that synapse with PFC pyramidal neurons (Vincent et al., 1994). To the extent that diminished GABAergic and/or DA inhibition is operative in schizophrenia, this finding suggests that haloperidol may have the functional effect of reasserting GABAergic inhibition in the PFC. This increase in GABAergic tone in some interneuron populations in the PFC could be the functional

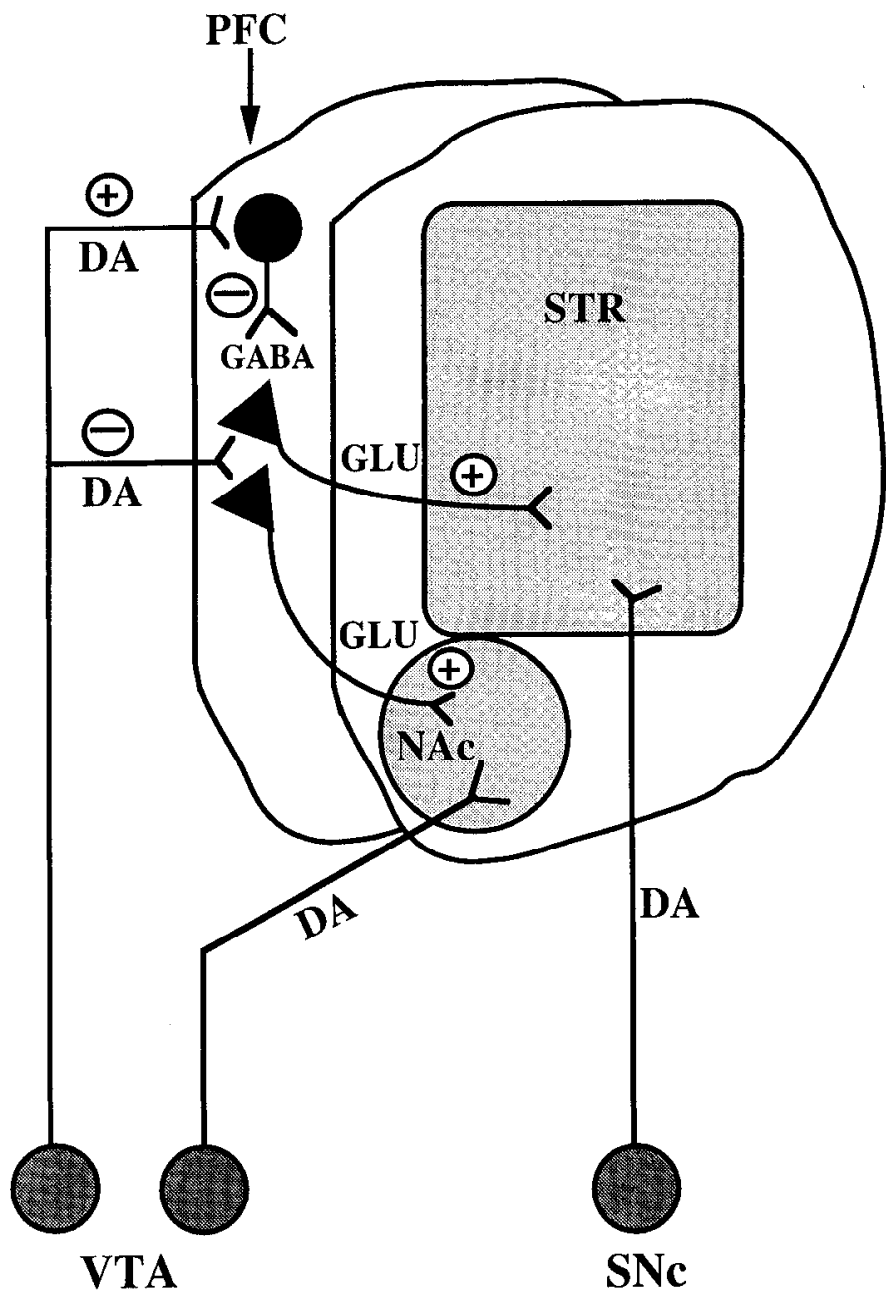

Figure 6. Schematic depiction of cortical glutamate regulation of subcortical dopamine pathways. DA derived from ventral tegmental neurons exerts an inhibitory influence on glutamate-containing pyramidal neurons in the PFC either directly, or indirectly via stimulation of GABA release from interneurons. According to current hypotheses about schizophrenia, decreased cortical DA or decreased GABA (e.g., due to fewer interneurons in the PFC) would predictably increase corticostriatal/accumbens glutamatergic output and, consequently, subcortical DA function. Haloperidol- and clozapine-induced increases in the levels of GluR1, which is enriched in GABAergic interneurons, would be expected to increase inhibition of corticostriatal/accumbens output and thereby oppose the hypothetical abnormalities in schizophrenia. Some of the anatomical relations depicted are not definitive. VTA, ventral tegmental area; $S N c$, substantia nigra pars compacta; $G A B A, \gamma$-aminobutyric acid; $G L U$, glutamate; STR, striatum; NAC, nucleus accumbens;,+- , excitatory, inhibitory synapses, respectively.

equivalent of the increases in GluR1 levels observed selectively in this brain region in the present study. It has been shown recently in monkey (Vickers et al., 1993) and rat (Martin et al., 1993; Fitzgerald et al., unpublished results) that immunoreactive GluR1 (but not other AMPA subunits) is enriched in a subpopulation of GABAergic interneurons in the PFC with only faint staining observed in pyramidal neurons. This observation raises the possibility that the clozapine- and haloperidol-induced increases in GluR 1 may be localized to PFC interneurons, the functional consequence of which may be to enhance GABAergic inhibition of pyramidal output to subcortical DA systems.

Finally, a third major finding of the present study is that clozapine regulated GluR2 protein levels in several brain regions; 
this was the only drug tested that regulated this subunit. The GluR2 subunit has recently gained significant attention because it appears to be an important determinant of $\mathrm{Ca}^{2+}$ flux through AMPA channels. Recombinant AMPA channcls that assemble from GluR1 or GluR3 subunits are permeable to $\mathrm{Ca}^{2+}$ and inwardly rectify; however, when GluR2 is expressed in combination with GluR1 or GluR3, the resulting AMPA channels are considerably less permeable to $\mathrm{Ca}^{2+}$ and show linear currentvoltage relations (for review see Hollmann and Heinemann, 1994). The ability of chronic clozapine to increase GluR2 levels in the nucleus accumbens, fronlal-parietal cortex, and hippocampus may represent a regulatory shift toward producing nascent channels that are impermeable to $\mathrm{Ca}^{2+}$ in certain subsets of neurons. This conclusion complements a recent finding that chronic clozapine also downregulates the metabotropic glutamate receptor subunit mGluR1 in the nucleus accumbens (L. W. Fitzgerald and E. J. Nestler, unpublished observations), a subunit which is known to mediate inositol-phosphate-induced increases in intracellular $\mathrm{Ca}^{2+}$ (for review see Hollmann and Heinemann, 1994).

In summary, chronic treatment with APDs produces regionspecific regulation of at least three of the known 16 glutamate receptor subunits. While further work is needed to define the functional impact these changes have on basal ganglia and cortical function and the pathophysiology of psychotic disorders, our findings indicate that adaptations in excitatory amino acid receptors may represent an important and novel mechanism through which APDs exert some of their long-term effects on brain function.

\section{References}

Akbarian S, Bunney WE Jr, Potkin SG, Wigal SB, Hagman JO, Sandman CA, Jones EG (1993) Altered distribution of nicotinamide-adenine dinucleotide phosphate-diaphorase cells in frontal lobe of schizophrenias implies disturbances in cortical development. Arch Gen Psychiatry 50:169-177.

Albin RL, Young AB, Penney JB (1989) The functional anatomy of basal ganglia disorders. Trends Neurosci 12:366-375.

Andersen PH (1988) Comparison of the pharmacological characteristics of $\left[{ }^{3} \mathrm{H}\right]$ raclopride and $\left[{ }^{3} \mathrm{H}\right] \mathrm{SCH} 23390$ binding to dopamine receptors in vivo in mouse brain. Eur J Pharmacol 146:113-120.

Anwyl R (1991) The role of the metabotropic receptor in synaptic plasticity. Trends Pharmacol Sci 12:324-326.

Bai G, Kusiak JW (1993) Cloning and analysis of the $5^{\prime}$ flanking sequence of the rat $N$-methyl-D-aspartate receptor 1 (NMDAR1) gene. Biochim Biophys Acta 1152:197-200.

Baldessarini RJ, Centorrino F, Flood JG, Volpicelli SA, Huston-Lyons D, Cohen BM (1993) Tissue concentrations of clozapine and its metabolites in the rat. Neuropsychopharmacology 9:117-124.

Beitner-Johnson D, Nestler EJ (1991) Morphine and cocaine exert common chronic actions on tyrosine hydroxylase in dopaminergic brain reward regions. J Neurochem 57:344-347.

Benes FM, McSparren J, Bird ED, SanGiovanni JP, Vincent SL (1991) Deficits in small interneurons in prefrontal and cingulate cortex of schizophrenic and schizoaffective patients. Arch Gen Psychiatry 48: 996-1001.

Benes FM, Vincent SL, Alsterberg G, Bird ED, SanGiovanni JP (1992) Increased GABA-A receptor binding in superficial layers of schizophrenic cingulate cortex. J Neurosci 12:924-926.

Berman KF, Weinberger DR (1990) The prefrontal cortex in schizophrenia and other neuropsychiatric: in vivo physiological correlates of cognitive deficits. In: The prefrontal cortex: its structure, function, and pathology (Uylings HBM, Van Eden CG, De Bruin JPC, Corner MA, Feenstra MPG, eds), pp 521-538. Amsterdam: Elsevier.

Bettler B, Boulter J, Hemans-Borgmeyer I, O'Shea-Greenfield A, Deneris ES, Moll C, Borgmeyer U, Hollmann M, Heinemann S (1990) Cloning of a novel glutamate receptor subunit, GLUR5: expression in the nervous system during development. Neuron 5:583-595.

Boulter J, Hollmann M, O'Shea-Greenfield A, Hartley M, Deneris F, Maron C, Heinemann S (1990) Molecular cloning and functional expression of glutamate receptor subunit genes. Science 249:10331037.

Carlsson M, Carlsson A (1990) Interactions between glutamatergic and monaminergic systems within the basal ganglia-implications for schizophrenia and Parkinson's disease. Trends Neurosci 13:272-276.

Collingridge GL, Singer W (1990) Excitatory amino acid receptors and synaptic plasticity. Trends Pharmacol Sci 11:290-296.

Creese I, Burt DR, Snyder SH (1976) Dopamine receptor binding predicts clinical and pharmacological potencies of antischizophrenic drugs. Science 192:481-483.

Csernansky JG, Wrona CT, Bardgett ME, Early TS, Newcomer JW (1993) Subcortical dopamine and serotonin turnover during acute and subchronic administration of typical and atypical neuroleptics. Psy chopharmacology 110:145-151.

Daly DA, Moghaddam B (1993) Actions of clozapine and haloperidol on the extracellular levels of excitatory amino acids in the prefrontal cortex and striatum on conscious rats. Neurosci Lett 152:61-64.

Deutch AY (1993) Prefrontal cortical dopamine system and the elaboration of functional corticostriatal circuits: implication for schizophrenia and Parkinson's disease. J Neural Transm 91:197-221.

Deutch AY, Moghaddam B, Innis RB, Krystal JH, Aghajanian GK, Bunney BS, Charney DS (1991) Mechanisms of action of atypical antipsychotic drugs: implications for novel therapeutic strategies for schizophrenia. Schizophr Res 4:121-156.

DiChiara G, Morelli M, Consolo S (1994) Modulatory functions of neurotransmitters in the striatum: $\mathrm{ACh} /$ dopamine/NMDA interactions. Trend Neurosci 17:228-232.

Farde L, Wiesel FA, Halldin C, Sedvall G (1988) Central D2-dopamine receptor occupancy in schizophrenic patients treated with antipsychotic drugs. Arch Gen Psychiatry 45:71.

Gellman RL, Aghajanian GK (1993) Pyramidal cells in piriform cortex receive a convergence of inputs from monoamine activated GABAergic interneurons. Brain Res 600:63-73.

Gerfen CR (1992) The neostriatal mosaic: multiple levels of compartmental organization. Trends Neurosci 15:133-139.

Grace AA (1993) Cortical regulation of subcortical dopamine systems and its possible relevance to schizophrenia. J Neural Transm 91:111134.

Grobin AC, Deutch AY (1994) Apomorphine increases extracellular GABA levels in the prefrontal cortex of the freely moving conscious rat. Soc Neurosci Abstr 20:1154.

Hollmann M, Heinemann S (1994) Cloned glutamate receptors. Annu Rev Neurosci 17:31-108.

Hollmann M, O'Shea-Greenfield A, Rogers SW, Heinemann S (1989) Cloning by functional expression of a member of the glutamate receptor family. Nature 342:643-648.

Hyman SE, Nestler EJ (1993) The molecular foundations of psychiatry. Washington, DC: American Psychiatric.

Ishii T, Moriyoshi K, Sugihara H, Sakurada K, Kadotani H, Yokoi M, Akazawa C, Shigemoto R, Mizuno N, Masu M, Nakanishi S (1993) Molecular characterization of the family of the $N$-methyl-D-aspartate receptor subunits. J Biol Chem 268:2836-2843.

Krystal JH, Karger LP, Seibyl JP, Freeman G, Delaney R, Bremner JD, Heninger GR, Bowers MB, Charney DS (1994) Subanesthetic effects of the noncompetitive NMDA antagonist, ketamine, in humans: psychotomimetic, perceptual, cognitive, and neuroendocrine responses. Arch Gen Psychiatry 51:199-214.

Lappalainen J, Hietala J, Pohjalainen T, Syvälahti E (1992) Regulation of dopamine $D_{1}$ receptors by chronic administration of structurally different $D_{1}$ receptor antagonists: a quantitative audioradiographic study. Eur J Pharmacol 210:195-200.

Leysen JE, Van Gompel P, Gommeren W, Woestenborghs R, Janssen PAJ (1986) Down regulation of serotonin-S2 receptor sites in rat brain by chronic treatment with the serotonin-S2 antagonists: ritanserin and septoperone. Psychopharmacology 88:434-444.

Lieberman JA (1993) Understanding the mechanism of action of atypical antipsychotic drugs: a review of compounds in use and development. Br J Psychiatry 163:7-18.

Martin LJ, Blackstone CD, Levey AI, Huganir RL, Price DL (1993) AMPA glutamate receptor subunits are differentially distributed in rat brain. Neuroscience 53:327-358.

Meltzer HY (1991) The mechanism of action of novel antipsychotic drugs. Schizophr Bull 17:263-287.

Moghaddam B (1994) Recent basic findings in support of excitatory 
amino acid hypotheses of schizophrenia. Prog Neuropsychopharmacol Biol Psychiatry 18:859-870.

Monaghan DT, Bridges RJ, Cotman CW (1989) The excitatory amino acid receptors: their classes, pharmacology, and distinct properties in the function of the central nervous system. Annu Kev Pharmacol Toxicol 29:365-402.

Monyer H, Sprengel R, Schoepfer R, Herb A, Higuchi M, Lomeli H, Burnashev N, Sakmann B, Seeberg PH (1992) Heteromeric NMDA receptors: molecular and functional distinction of subtypes. Science 256:1217-1221.

Moriyoshi K, Masu M, Ishii T, Shigemoto R, Mizuno N, Nakanishi S (1991) Molecular cloning and characterization of the rat NMDA receptor. Nature 354:31-37.

Nakanishi S (1992) Molecular diversity of glutamate receptors and implications for brain function. Science:597-603.

Paxinos G, Watson CW (1986) The rat brain in stereotaxic coordinates, 2d ed. Sydney: Academic.

Penney JB, Wullner U, Catnia MV, Standaert DG, Testa CM, I.andwehrmeyer GB, Dure LS, Young AB (1993) Glutamate receptor expression in rat striatum: effect of deafferentation. Soc Neurosci Abstr 19:1355.

Peroutka SJ, Snyder SH (1980) Relationship of neuroleptic drug effects at brain dopamine, serotonin, $\alpha$-adrenergic, and histamine receptors to clinical potency. Am J Psychiatry 137:1518-1522.

Petralia RS, Yokotani N, Wenthold RJ (1994) Light and electron microscope distribution of the NMDA receptor subunit NMDAR1 in the rat nervous system using a selective anti-peptide antibody. J Neurosci 14:667-696.

Puchalski RB, Louis J-C, Brose N, Traynelis SF, Egebjerg J, Kukekov V, Wenthold RJ, Rogers SW, Lin F, Moran T, Morrison JH, Heinemann SF (1994) Selective RNA editing and subunit assembly of native glutanate receptors. Neuron 13:131-147.

Retaux S, Besson MJ, Penit-Soria J (1991) Opposing effects of dopamine D2 receptor stimulation on the spontaneous and the electrically evoked release of $\left[{ }^{3} \mathrm{H}\right] \mathrm{GABA}$ on rat prefrontal cortical slices. Neuroscience 42:61-71.

Reynolds GP, Garrett NJ, Rupniak N, Jenner P, Marsden C (1983) Chronic clozapine treatment of rats down-regulates cortical 5-HT2 receptors. Eur J Pharmacol 89:325-326.

Roth BL, Ciaranello RD (1991) Chronic mianserin treatment dccrcases $5-\mathrm{HT}_{2}$ receptor binding without altering $5-\mathrm{HT}_{2}$ receptor mRNA levels. Eur J Pharmacol 207:169-172.

Rupniak NMJ, Mann S, Hall MD, Fleminger S, Kilpatrick G, Jenner $\mathbf{P}$ Marsden CD (1984) Differential effects of continuous administration for 1 year of haloperidol or sulpiride on striatal dopamine function in the rat. Psychopharmacology 84:503-511.

See RE, Ellison G (1990) Comparison of chronic administration of haloperidol and the atypical neuroleptics, clozapine and raclopride, in an animal model of tardive dyskinlesia. Eur J Pharmacol 181:175186.

Seeman P, Guan HC, Van Tol HHM (1993) Dopamine D4 receptors elevated in schizophrenia. Nature 365:441-445.

Siegel SJ, Brose N, Janssen WG, Gasic GP, Jahn R, Heinemann SF, Morrison JH (1994) Regional, cellular, and ultrastructural distribution of $N$-methyl-D-aspartate receptor subunit 1 in monkey hippocampus. Proc Natl Acad Sci USA 91:564-568.

Tamminga CA, Gerlach J (1987) New neuroleptics and experimental antipsychotic in schizophrenia. In: Psychopharmacology-the third generation in progress (Meltzer, HY, ed), p 441. New York: Raven.

Titeler M, Seeman P (1980) Radioligand labeling of pre- and postsynaptic dopamine receptors. Adv Biochem Psychopharmacol 24:159.

Trevisan L, Fitzgerald LW, Brose N, Gasic GP, Heinemann SF, Duman RS, Nestler EJ (1994) Chronic ingestion of ethanol up-regulates NMDAR1 receptor immunoreactivity in rat hippocampus. J Neurochem 62:1635-1638.

Vickers JC, Huntley GW, Fdwards AM, Moran T, Rogers SW, Heinemann SF, Morrison JH (1993) Quantitative localization of AMPA/ Kainate and kainate glutamate receptor subunit immunoreactivity in neurochemically identified subpopulations of neurons in the prefrontal cortex of the macaque monkey. J Neurosci 13:2982-2992.

Vincent SL, Adamec E, Sorensen I, Benes FM (1994) The effects of chronic haloperidol administration on GABA-immunoreactive axon terminals in rat medial prefrontal cortex. Synapse 17:26-35.

Volavka J, Cooper T, Czobor P, Bitter I, Meisner M, Laska E, Gastanaga P, Krakowski M, Chou J, Crowner M, Douyon R (1992) Haloperidol blood levels and clinical effects. Arch Gen Psychiatry 49:354-361.

Weinberger DR (1987) Implications of normal brain development for the pathogenesis of schizophrenia. Arch Gen Psychiatry 44:660-669.

Wenthold RJ, Yokotani N, Doi K, Wada K (1992) Immunochemical characterization of the non-NMDA glutamate receptor using subunitspecific antibodies: evidence for hetero-oligomeric structure in rat brain. J Biol Chem 267:501-507.

Werner P, Voigt M, Keinänen K, Wisden W, Seeburg PH (1991) Cloning of a putative high-affinity kainate expressed predominantly in hippocampal CA3 cells. Nature 351:742-744.

Wilk S, Stanley M (1978) Clozapine concentrations in brain regions: relationship to dopamine metabolite increase. Eur J Pharmacol 51: 101-107.

Wüllner U, Brouillet E, Isacson O, Young AB, Penney JB (1993) Glutamate receptor binding sites in MPTP-treated mice. Exp Neurol 121: 284-287. 